\title{
Building a Sales Policy
}

\section{By John M. Bruce}

Vice-President, the Remington Typewriter Company, New York, N. Y.

$\mathrm{T}$

HE Taylor System, as applied to production or distribution, means more than a careful study or analysis of the motions that must be gone through to produce, with the least amount of effort, in the shortest possible space of time, the results desired, and then have adequate payment made for those efforts.

\section{The Philosophy of the Taylor System}

Mr. Taylor evolved a science of shop management based on a theory of philosophy. When attempts to install the Taylor System of shop management are made by those who have read the science from Mr. Taylor's manual-and it is mighty hard reading-without securing the real underlying philosophy, the result is always as disastrous as it would be if we set a high-speed, steel cutting tool to work without a guide. We would cut a lot of material, but we would also destroy a lot. We can do just as much cutting, maybe more cutting, without as with the guide, but we won't produce anything.

The philosophy of the Taylor System is absolutely basic and fundamentally sound. It is applicable to every type of industrial effort. The application of that philosophy is a science, and a highly technical science, based on certain specific laws as laid down by Mr. Taylor and demonstrated by the illustrations in his manual of shop practice. The man who attempts to install the Taylor System without a broad and understanding knowledge of the Taylor philosophy, without a comprehensive grasp of the principles underlying the science of the Taylor System, is courting disaster.

The Taylor System is not, and never can be made to work by forcing the business to meet the cut-and-dried rules such as are illustrated in Mr. Taylor's manual. Mr. Taylor never did that himself. The illustrations he gives are some of the applications he made where a particular type of installation was the type exactly fitted to solve that particular company's own problem. The man 
who tries the cut-and-dried system will empty the coffers of his company just as rapidly as a preacher would empty the pews of his church if he tried preparing his sermons with a rubber stamp.

It is folly to ask a laborer in the foundry cleaning room to wait for a share of the profits until the finished product of the factory has been sold-yet this has been done. Offers have been made to laborers in the foundry that, if they worked hard they would share the profits at the end of the year. Although a laborer might do his work faithfully and infinitely well, still in other departments of the business, over which he had no possible control or even knowledge, the proposition might fall flat. You cannot pay a man in a lower place in business for work over which he has no control. You can pay him for what he does himself and reward him immediately for his effort, and you will get the effort you want. You will not get it in any other way.

The difference between the man who earns a daily wage and the man who earns a yearly income is only to a very small degree a difference of intellect. Professor Scott and a good many others after having brought to bear on the subject the best psychological study, believe that the difference between the intellects of the average normal men, the intellectual power, is only about ten per cent, at a maximum. The huge difference between men is not in intellect, not in brain capacity, but in imagination. One man can see a reward and work for it if it is an hour away; another man can see a reward and work for it if it is five years away, or ten years away, or a lifetime away; and you can measure a man's capacity for achievement by the distance he is willing to place between himself and his reward. Maybe it is by the square of the difference.

Every time the Taylor System has been put piecemeal into a factory, it has overbalanced the department into which it has been put, and the result has been worse than no Taylor System. You cannot speed up one end of the business and not speed up the whole business. People do not seem always to realize that you have to coördinate a proposition of that kind. You cannot start a high-speed tool working in one department and not in all departments. You have to sell the philosophy of the proposition to your whole institution before you can apply the science of the proposition to any part of your institution. 
When we apply the Taylor System to a sales department, a distribution department, we have to go back before the beginning. We have - to use an Irish "bull"- to go back and start before we start. We have to find out where we are, where we are bound for, what we want to do and what it is going to cost us before we try to do anything.

The average steering of the business ship, especially the sales ship, seems to partake of issuing orders to a sea captain, taking his chart and his compasses away from him and saying, "Go outside of Sandy Hook and sail now-sail-sail! All we want you to do is to sail." These are the orders lots of salesmen get. They don't say "sail"- they say "sell." They are told to go outside of Sandy Hook and sell. The ship that goes outside of Sandy Hook and sails and sails and sails is going to land on the rocks, and so is the sales department that guides its salesmen in that way. The end of one is just as certain as the end of the other.

\section{The Specialty Manufacturer's Average Profit}

Take the case of two large and eminently successful specialty manufacturers. They were making a large line of office appliances, and when asked what branches of their business paid and what branches did not pay, they said, "Oh! everything pays." "How do you know everything pays?" "Why," they said, "We know how much money we get in and we know how much money we pay out; we take all the costs and we allow enough for a depreciation in the factory, and then we subtract the amount we paid out from the amount we took in, divide it by the total number of goods made, and that is the average profit." That is the average business way of looking at it, but it is not the average profit or anything like the average profit.

On a very large percentage of the products that those people sold they took in exchange goods, that is, used material, at a very large price in order to stimulate a new sale. After some weeks of explanation and argument those gentlemen were finally convinced that every one of those sales was made at an absolute loss. In other words, over half of their business was done at a loss and the other half carried an outrageous profit.

Now as long as similar line concerns were doing this, it was all right- or rather it was not all right, but they were all fairly safe, 
because the whole industry would not be likely to go to the wall. It is mighty hard for the whole industry in any line to go to the wall, and if nobody in the industry knows how to steer the ship they are all pretty nearly on the same basis, and they are all likely to arrive at a reasonable amount of profit.

\section{Improvements in a RubBer Company's Business}

A large rubber company that has grown as fast or faster than any other company in its line in the United States decided to call in an outsider to look over the business and see where there was any room for improvement. The consultant was told before he went in that what the officers of the company for the most part really wanted was a gold badge that there was not anything wrong, that the thing was perfect. But they did not get that. The president, the man who decided on the investigation, got what he wanted-the disagreeable facts. The most surprising development in analyzing the proposition was to find the enormous number of orders, even in proportion to the very large amount of business these people did. They had a business that was absolutely wholesale. They sold no goods at retail whatever. They sold through the dealer, even to the point of refusing to sell to their own board of directors. Further investigation disclosed, for example, a customer of theirs, a wholesale customer, whose business ran about four thousand dollars a month. In one month's accounts examined he had bought six hundred separate items from them. There were six hundred separate charges to make up a total of four thousand dollars. It was necessary to ascertain the unit cost on what it cost to handle each charge through the books of that company. They were doing it very reasonably. They had an efficient bookkeeping department, and they were making each charge for a dollar twenty-eight cents, which is a low cost. You may think that was high, and it is generally considered high when mentioned, but if you will make a unit examination on your own charges you will find they are higher, nine times out of ten.

In trying to find out why they had six hundred charges from that man with a four thousand dollar account-why he should buy six hundred items in one month-it was found that they had established a very scientific practice of demanding that their 
dealers carry a stock of their products in order to get the advantage of the trade discount, and they made each dealer stock up at the beginning of the season. But they never said anything to the dealer about continuing to carry stock.

It was the custom of that trade to give service. Each of the houses in that industry had originally been retail houses, dealing direct with the consumer from the manufacturer. The concern in question had seventy branch houses for the purpose of retail trade in every city of any size in the United States. When they decided that the trade had grown sufficiently, so that it was a better policy for the trade to handle their product than for them to handle it direct, that the trade had stabilized to that point, they still maintained their retail equipment and retail service which they had been perfectly able to maintain at the retail price, and gave the benefit of it to the wholesaler. The wholesaler bought a stock according to the size of the town in which he was located and according to the territory he covered, as they asked him to buy at the beginning of the year, and then he never bought any more stock. He just picked it up as he sold. For instance, this man that had the six hundred orders in one month stated: "I have a stock clerk who fills all our orders that come in from consumers. If a customer comes in and buys a box of tire patches for twenty-five cents we deliver them to him, and our stock clerk goes to the telephone and calls up the company's branch, and they send over another box of tire patches. We keep our stock automatically. It is a cinch."

This was reported to the officers of the company and they were shown that on any order below a certain number of dollars, one dollar and twenty-eight cents took all the profit and made it a loss. It was also discovered that forty per cent of all the orders that concern received were executed at a loss.

"Well," they said, "of course, that is necessary. It is the custom of the trade. Everybody does it. If we didn't do it we would be annihilated. Everybody gives that kind of service to the dealer. We deliver to him any time he wants."

He was not talking about the "customs of the trade"; he meant the "superstitions of the trade"-he was using the wrong word. Look in the dictionary.

When corrective measures were offered, finally, after a great 
amount of argument they said, "All right, go ahead and try it that way." It was tried out in one city, not giving the dealer any special inducement, and simply a letter written to every customer they had in that city telling him these facts: that forty per cent of all the orders given the company were taken at a loss; that they could not afford to do business that way, and they knew he did not want them to go on doing business that way; that he wanted them to make money, even as they wanted him to make money. They went on to tell these customers that they only asked them to pay their bills once a month. It made no difference to them whether they bought ten orders a day or one order a week, and that if they would take a little pains with their stock they could order less frequently.

The cost of selling, which ran at a certain percentage in that trade, was analyzed and the salesman, who had been on a salary basis was placed on a commission basis, that is, a task and bonus basis. It worked out scientifically. We will say the original cost was two and a half per cent for selling. Under the new plan, if a salesman brought in an order for less than a hundred dollars in a large city, he got half of one per cent; if the order was from one hundred to two hundred fifty dollars he got one per cent; from two hundred fifty to five hundred dollars, two and a half or three per cent; above five hundred dollars four per cent; and if it was above a thousand dollars he got five per cent.

They paid twice as much as before for the kind of orders wanted - the orders above a thousand dollars - and paid almost nothing for the orders they did not want.

At the end of sixty days this concern was doing a twenty-five per cent larger business in that city. They had had six automobile trucks, with two shifts of drivers on each truck, making their deliveries. At the end of that time they had three automobile trucks, with one shift of drivers on each truck working eight hours a day delivering twenty-five per cent more goods. They delivered to the north side of that city twice a week, to the west side of the city twice a week, and to the south side twice a week, and when a man called up out of time they delivered by express at his expense.

There was no trouble about it. They did not lose a customer. A good many of the customers said they wondered it had not 
been done before. That was all that occurred to them. Now, that is the difference between allowing a thing to go on because it is the custom of the trade, or the superstition of the trade, and stopping it; and it can always be stopped.

\section{Experience of an Ammunition Concern}

Another interesting thing happened a little while ago with a tremendously successful and very large concern in the ammunition business. One of that concern's lines was making shot-gun shells. They wanted to secure the services of the best motion study expert they could get hold of to speed up the transfer of machines from one kind of loading to another. They said, "We have eighteen thousand different changes in loads that we sell regularly in our plant here, and every time we change a load to fill an order we have to stop and reset the machine. We have made a study of it and find that our machines are out of use and are not loading forty per cent of the time. They only load sixty per cent of the time, and they are idle in change forty per cent of the time. If we could speed them up we might arrange to cut it down to twenty per cent."

Upon inquiry as to how many loads are necessary to cover all the kind of game that are shot, after figuring out the number of loads and also how many kinds of powder were necessary and the other things that a customer had a legitimate reason for buying, the result was less than a hundred loads instead of eighteen thousand. Then a basis was worked out by which a customer could get the standard loads at the standard price paying a little excess for the special loads. They put five machines to work on the special loads, and the other three hundred and ninety-six machines on standard loads, set permanently, so many different machines to each load, according to the class of loads that were wanted. So, instead of doing a lot of work to save time in making the changes, they did something else, they eliminated the changes.

\section{The Dividend Menace}

The writer wants to pay a tribute to one of the brightest men he ever met. He would not like it if we mentioned his name, but he is the president of the self-same rubber company mentioned before. 
When the writer went there, unlike his associates who wanted a medal for their brilliance, he said: "Our business has grown a hundred times in twelve years. Nothing ever grew so fast as that that didn't grow as soft as a mushroom. It is fine; everybody in the trade is getting more orders than he can fill and conditions are lovely, but they won't stay that way. When it comes to hard times, when it comes to where everything has to be cut the chilledsteel tool is the only one that is going to last. The mushroom tools are going to wear out. I want mine chilled. Just let's case-harden this company and cut the waste and the soft spots. You are here for a surgical operation on a successful company." There are mighty few men who would have brains enough to talk about surgical operations in the face of dividends. Dividends are the greatest choker of ambition that there is in the world. As a matter of fact, the principal reason you are paying dividends is because your competitor does not know any more about his business than you know about yours. There was a concern that paid dividends because they marked up the price of their second-hand goods every year-the price of stock on hand. They paid dividends for seven or eight years on that. Then the bankers took what was left over for reorganization.

It is interesting to see how many different "slants" there are on the business problem. You can watch the wheels go round on the inside of a great many different businesses, and never see two businesses with the same problems. There is a problem in every business and every problem is a different problem.

\section{Sales Management in a Packing Business}

For instance, there was a packing business that had grown tremendously. They started in with canned meats. They saw an opportunity to buy out another concern and get into the condensed milk business, and they made money. They told their canned meat salesmen to sell condensed milk. As soon as they got condensed milk they got a new sales manager for the condensed milk line. The old salesmen looked around and said, "Who is setting the pay for us? Who O.K.'s any increases in salary?" They saw it was the old sales manager who did it. The new sales manager said, "You have to sell condensed milk"; but the salesmen went right ahead and sold what they were paid for selling 
and let the new sales manager talk, and whatever he said seemed to hit something and bounce off-just seemed to bounce off.

They got a California fruit proposition and added that to the line, and they got a sales manager for that. Then they bought a vegetable proposition, and a Hawaiian pineapple proposition, and eight or ten other lines, and finally they had eight or ten sales managers. The new sales managers could not get the old sales force to do their work, and they began demanding sales forces of their own. Some got them and some did not, according to the "pull" they happened to have with the institution. The condensed milk man had a big "pull," and he got a hundred salesmen. The California fruit sales manager was not popular, and he had only twenty salesmen. They had five hundred territories that they ought to have covered, and they had four hundred salesmen covering them, many of them overlapping.

The cost of getting orders in that business was very low, much lower than it is in most lines, because it was an established trade. They had established relations with their customers, and practically every call of the salesman resulted in an order. Just think what we would do if that were so in the specialty business. But only four per cent of those orders had more than one product on the order, and only two per cent had more than two products on the order, and half of one per cent had more than five products on the order, with a company having about twenty-five lines. Moreover, the salemen were all working against each other, because the great problem in the grocery trade is the credit ability of the little grocer. The canned meat man, having a good staple line, would go in and sell ten cases of canned meat, and the grocer was out of business for a month, as far as credit went with the house. They never thought of how much better it would have been to sell him one case of canned meat and one case of condensed milk and one case of pineapple and one case of asparagus, and one case of something else and get repeated orders. Nobody ever thought of that, and if he had, they would have said it could not be done.

Well, when they began paying the salesmen at the rate of a quarter of one per cent for an order made up of one product, at five per cent when it had four products, and ten per cent when it had seven products, they began to get the orders with seven products. It would surprise you how those orders came in. 
It could not be done; but it was done, and the cost per sale dropped 'way down because the cost per product dropped 'way down.

The cost per sale in that business was a dollar and eighty-seven cents, including the salesman's salary and traveling expenses and the overhead, and it might just as well have covered five or six products as one product. It did not make any difference, he had to make the call just the same. They could save a lot of money under this plan because they cut out a lot of that traveling.

As soon as they had this plan working they abolished all the overlapping sales forces; the country was redistricted and the sales managers of the various lines were made district sales managers with one general sales manager and the proposition was worked out with very much smaller territories for each man. Each man covered his trade and saw that that trade had a complete line of that company's products which his class of customers could use. He stopped being a salesman and became an adviser and helper of his customer. He did advertising work and backed up the advertising department by the proper kind of distribution work rather than as a star salesman.

\section{The Problem of the Tobacco Manufacturer}

In the tobacco business the problem is not a problem of the size of the orders. It is a problem of distributing the product and getting it where it can go to the customer the instant he asks for it, and getting it to him fresh. All of the tobacco manufacturers of any repute have the practice of taking back any product that any dealer has ever bought from them, at the price he paid for it, at any time rather than allow that dealer to sell what are technically known as "funky" goods to the public-that is, stale tobacco--and they are right. Every time that you are convinced by advertising that you should smoke "Darum" cigarettes the company has invested about seven dollars in convincing you, and it costs them only about ten cents to take back a stale package of "Darum" cigarettes rather than let you buy them. If you buy a stale package, you do not say, "That is a stale package." You say, "Darum cigarettes are rotten."

One of these tobacco manufacturers wanted their salesmen to do a lot of different things in the dealer's store. They wanted them 
to arrange the dealer's shelves, to make an attractive display of their product, to put their lines where they would be featured and where they would catch the public's eye. They wanted the salesmen to put up advertising matter in the dealer's store. They wanted the salesman, most of all, to demonstrate their products. They told the salesmen all these things, and paid them for the quantity of sales; and the company kept on getting volume, but the salesmen slept on the other stuff. That was the history of the business.

There was one brand of world-famous cigarette tobacco, you all know the brand-which began to slip about five years ago. Everybody wanted to know why. This brand was the bread and butter of the company - and cake, too. Nobody knew why it was slipping, but everybody had a different theory. There was a very easy way to find out, just by preparing a questionnaire and sending it out to the salesmen and getting answers. The salesmen were paid five cents each for the answers and twenty thousand answers were received in three weeks. These were put on the Hollerith machine, and the big question was answered in about two hours. The answer was that the men under twenty-five did not know how to roll the tobacco into cigarettes. The five cent cigarette had come along since those men started to smoke and they had never learned to "roll their own." They then began paying the salesmen for what they wanted them to do-teach the rolling of cigarettes. They paid for every effort they wanted the salesman to make, after studying how much time that effort would consume and how much it would produce for the company, and the desired results were obtained. There is no other way to get them.

\section{The Typewriter Business and the Exchange Problem}

In the typewriter business the problem has always been the exchange problem. Everybody said it was the curse of the industry, but the salesman was paid his commission on the exchange allowance value of the second-hand machine and the cash he brought in. You never saw a salesman who would not rather buy something than sell something, that is, it is easier to buy than it is to sell, and when you buy a second-hand machine and give a new machine for it, with a small amount of cash thrown in, and 
get the same commission, which would you do? That is what the salesmen did!

They not only did that, but automatically that meant that if the room you are in represented the field where the second-hand machine was and the whole area of New York City represented the area where no machines were, where the salesmen could go out and create a new sale, they stayed in your room, and all the competitors' salesmen followed each other. One competitor's salesman followed another competitor's salesman around the rat chase to try to take a prospect's old machine away from him and give him a new one in place of it, because the salesman got his commission on it, and it was easy money. Just as soon as that practice was eliminated and a penalty put on the trading in of second-hand machines, and the salesmen given a reward for the cash sale, exchange sales dropped in three months from seventyone per cent to twenty-two per cent.

\section{The Importance of Calis in Salesmanghip}

In every success in selling that the writer has ever had anything to do with, the basis of that success has been in the number of calls that a salesman makes. You cannot make sales unless your salesman makes a call. He has to see the people and interest them in what you are trying to sell. Everybody holds up his hands in horror at the idea of paying a salesman for making calls, but that is what you do when you pay him a salary. Regular salaries do not stimulate a salesman to his best efforts. It is better to give him a drawing account and pay him so much for every call he makes against that drawing account.

You can send out a circular in an envelope for ten cents apiece, and the destination of most of these circulars is the wastebasket. Why not pay your salesman ten cents to call on a man, and say, "Mr. Jones, I am from So-and-so, and I want to talk to you about so-and-so"? It is worth more than the circular, because it does not get thrown in the wastebasket, because the man has to listen to him to that extent. You do not pay unless he says that to the man. If you can teach a man what to say about your product, I do not care what your product is, and you can make him go through the motions of seeing people and making that statement about your product twenty times a day, there is not any product 


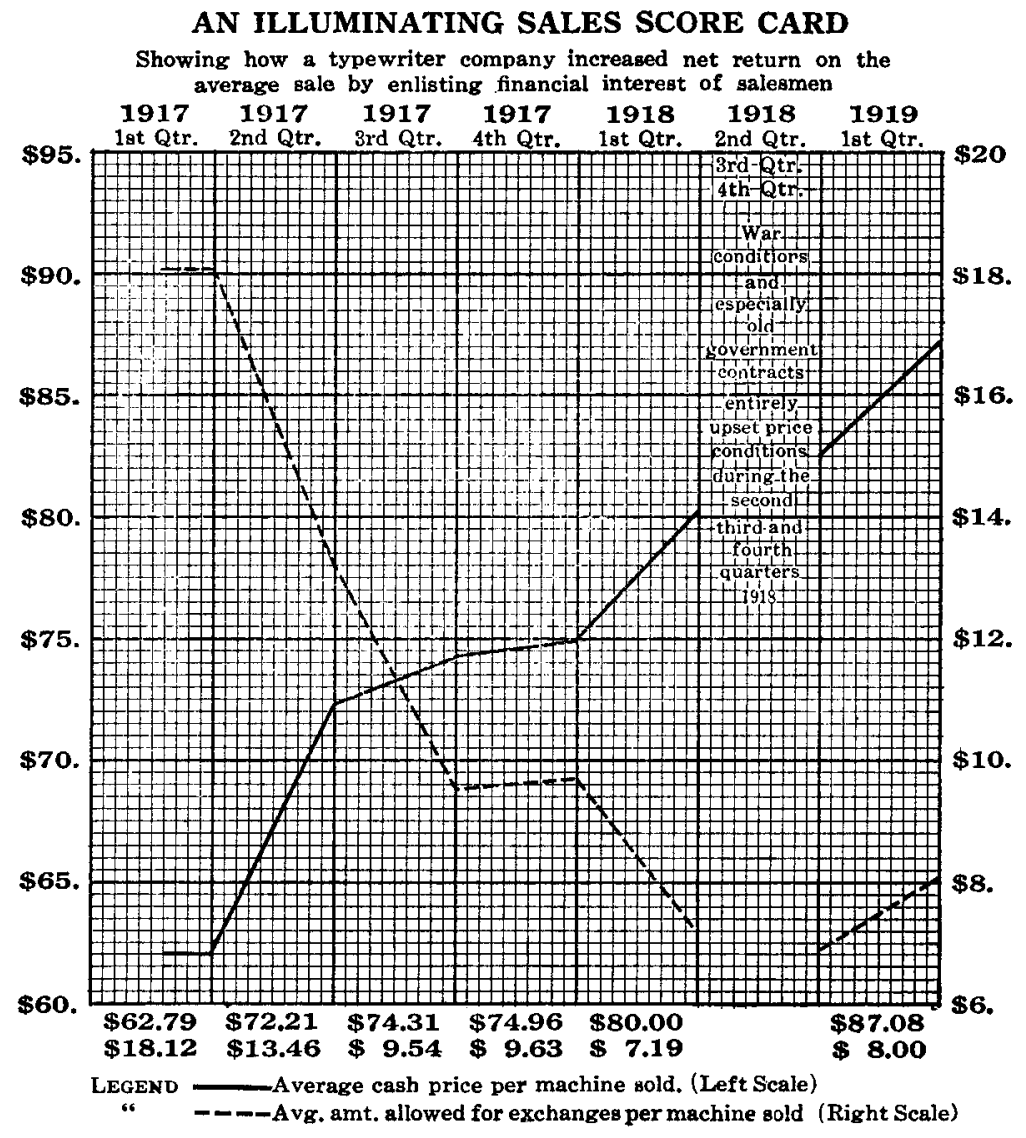


in the world where he will not connect with some sales. You cannot continue to expose yourself to the disease that often without getting measles.

There was a salesman down in Louisville that had been hanging on by his eyebrows. He just sold a minimum amount of goods--enough almost to justify his drawing account each month, and, of course, with the old drawing account system, which is a horrible handicap to a man. He starts out in debt to the company fresh every month, and the first three quarters of the month's work he is just making up a debt and, oh, how we love paying debts! This is the position you put your salesman in when you work under that plan.

The bonus system was all figured out and the salesmen were told: "You haven't got any debt to pay. All you have to do is make calls. If you make enough calls and demonstrations the price of those will pay your drawing account in cash, and all the commissions you make on sales will be 'velvet.' Of course, the commission is a little smaller, but you ought not to mind that." Now when they were told this the "wise guys" did not believe it. But the man we are discussing, not being very smart, believed it. He went out and believed he could make money that way.

He went to the tallest office building in Louisville and started at the top. He walked into the first door he saw and said, "Mister, want to buy a__ typewriter?" and the man said "No!" $\mathrm{He}$ went to the next door and said, "Want to buy a-typewriter?" and the man said, "No!" He made eighty calls a day that way, and was paid for them. The first month he made nine sales. That was more than he had ever made in a month before.

Some of the people in the company were very much concerned and thought the salesman was being paid a tremendous commission for those sales. However, they were assured there was no cause for worry and induced to let the experiment run along. The next month the people that fellow called on began to call him up. Remember, he was a rotten salesman-he is yet-but they started taking machines away from him. There were people who said, "Yes, I want a typewriter. I haven't seen a salesman around here for ages. Come in, for God's sake, and let me buy it," and he sold those people. The second month he had twentyeight sales, and he has been averaging over thirty sales ever since. 
Thirty sales a month is pretty good, and he has done it just simply because he has exposed himself to the sales.

\section{Reward for Sales}

After one has worked out a system for making a salesman call on prospective clients and pressing the argument in favor of the merchandise the next step is to decide on the most profitable lines of trade, and stress the reward for sales in these lines, so that it will be easier for the salesman to make money doing the thing that will be difficult than the thing that is easy.

For example, it is, of course, easier to trade out an old machine at a large allowance and sell a new machine, thus securing only a small cash difference, than it is to make a straight sale of a new machine for all cash; but, if the reward to the salesman is scientifically adjusted so that the salesman with the same effort will make more money on straight cash sales than he will make on many more of the easy exchange sales, the salesman rapidly finds that the way to make money is to go to the places where typewriters are not placed and create new business rather than follow a competitor's salesman around from one office which is stocked up to another trying to get out exchanges.

It is on this basis that the bonus system has been worked out for the sale of typewriters and the results are shown in the accompanying chart (see page 299).

That is all there is to the Taylor System, just common sense, just finding out what you want done, getting a policy outlined, deciding just how much effort is required to execute the various steps of that policy, and then paying for those steps on a square and just basis to your salesmen. In that way you are bound to get results.

The acid test of any business policy, in the last analysis, is this: Is your business policy square to your customer and profitable to your salesmen? Is it square to your salesmen and profitable to your house? If you can answer those questions in the affirmative there is not any business policy that can possibly fail. Absolutely, it cannot be done. You cannot answer these questions in the affirmative and have your policy wrong. 